\title{
Erratum to: Mesozooplankton distribution patterns and grazing impacts of copepods and Euphausia crystallorophias in the Amundsen Sea, West Antarctica, during austral summer
}

Doo Byoul Lee $\cdot$ Keun Hyung Choi $\cdot$

Ho Kyung Ha $\cdot$ Eun Jin Yang $\cdot$ Sang Heon Lee $\cdot$

SangHoon Lee $\cdot$ Hyoung Chul Shin

Published online: 12 June 2013

(C) Springer-Verlag Berlin Heidelberg 2013

Erratum to: Polar Biol

DOI 10.1007/s00300-013-1314-8

We would like to make the following corrections to the original article. Firstly, in Materials and Methods, 3rd

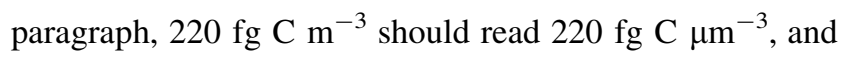
secondly, in Acknowledgements, the correct project numbers are Grant No. PP13020 and Grant No. PE11050.

The online version of the original article can be found under doi:10.1007/s00300-013-1314-8.

D. B. Lee · H. K. Ha · E. J. Yang · S. Lee · H. C. Shin ( $ه)$ Division of Polar Climate Research, Korea Polar Research Institute, Get-Pearl Tower, 12 Gaetbeol-ro, Yeonsu-gu, Incheon 406-840, Korea

e-mail: hcshin@kopri.re.kr

\section{K. H. Choi}

Ballast Water Center, Korea Institute of Ocean Science and Technology, Ansan 426-744, Korea

\section{S. H. Lee}

Department of Oceanography, Pusan National University, Busan 609-735, Korea 